\title{
Composição e qualidade de pólen apícola coletado em Minas Gerais
}

\author{
Anna Frida Hatsue Modro(1), Dejair Message ${ }^{(1)}$, Cynthia Fernandes Pinto da Luz ${ }^{(2)}$ \\ e João Augusto Alves Meira Neto(3)
}

\begin{abstract}
(1)Universidade Federal de Viçosa (UFV), Dep. de Biologia, Apiário Central, Av. P.H. Rolfs, s/no, CEP 36570-000 Viçosa, MG. E-mail: fridamodro@gmail.com, dmessage@ufv.br (2)Secretaria do Meio Ambiente de São Paulo, Instituto de Botânica, Seção de Dicotiledôneas, Av. Miguel Estéfano, no 3.687, Água Funda, CEP 04301-902 São Paulo, SP. E-mail: cyluz@yahoo.com.br (3)UFV, Dep. de Biologia Vegetal, Lab. de Ecologia de Ecossistemas. E-mail: j.meira@ufv.br
\end{abstract}

\begin{abstract}
Resumo - O objetivo deste trabalho foi avaliar a influência das composições florísticas locais sobre a qualidade do pólen apícola, em dois apiários de Minas Gerais. Em cada apiário, foram instaladas cinco colméias de Apis mellifera (L.). A flora polinífera foi identificada nas proximidades dos apiários. As bolotas de pólen foram coletadas de agosto a dezembro de 2005. A análise melissopalinológica foi realizada pelo método padrão europeu. Foram realizadas análises nutricionais do pólen relativas à porcentagem de matéria seca, orgânica e mineral, à proteína bruta, ao extrato etéreo e aos carboidratos totais. Foi realizada correlação de Spearman entre os componentes nutricionais e os tipos polínicos ocorrentes. No apiário UFV, a flora polinífera predominante apresentou espécies ornamentais com hábito arbóreo, e no apiário Mesmel predominaram as espécies da pastagem abandonada com hábito herbáceo. A composição nutricional do pólen coletado não apresentou correlação com a diversidade de tipos polínicos, mas apresentou correlação com a predominância de tipos polínicos específicos. As diferentes composições florísticas influenciam na qualidade do pólen apícola, e a coleta em diversas fontes de alimento, pelas abelhas, é importante para a obtenção de uma dieta mais equilibrada.
\end{abstract}

Termos para indexação: Apis mellifera, palinologia, recurso alimentar, alimentação das abelhas.

\section{Nutritional composition and quality of bee pollen collected in Minas Gerais, Brazil}

\begin{abstract}
The objective of this work was to assess the influence of the local floral composition on the quality of apicultural pollen collected in two apiaries, in Minas Gerais State, Brazil. Five hives of Apis mellifera (L.) were installed in each apiary. The polliniferous flora in the proximity of the apiaries was identified. The pollen loads were collected from August to December, 2005. The melissopalinological analysis was carried out following the standard European method. Nutritional analyses of pollen were performed related to percentages of dry, organic and mineral matter; to raw protein; to ether extract; and to total carbohydrates. Spearman correlation was carried out between nutritional components and pollen types. In the UFV apiary, the predominant polliniferous flora presented ornamental species with arboreous habitus, and in the Mesmel apiary, it presented species of abandoned cattle pasture with herbaceous habitus. The nutritional composition of the collected pollen showed no correlation with the diversity of pollen types, however, it showed correlation with the predominance of specific pollen types. Different floral compositions influence the quality of pollen collected by bees; and its collection by bees, in various sources, is important to obtain a more balanced diet.
\end{abstract}

Index terms: Apis mellifera, palinology, food resource, bee feeding.

\section{Introdução}

O pólen coletado nas anteras das flores é essencial para a nutrição das abelhas Apis mellifera L., pois provê recurso de proteína principalmente para larvas e adultos (Zerbo et al., 2001). Segundo Crailsheim (1990), o consumo de pólen pelas abelhas nutrizes é importante, pois elas só produzem a geléia real a partir dos nutrientes liberados pela digestão do pólen, que é metabolizado pelas células de suas glândulas hipofaringeanas e mandibulares.
Para o homem, muitos benefícios são atribuídos ao consumo do pólen, como fortificante extraordinário do organismo, estimulante e gerador de bem estar e vigor físico, além de corrigir a alimentação deficiente, o que resulta em equilíbrio funcional (Kroyer \& Hegedus, 2001).

O pólen é rico em proteínas, que servem de matéria prima para o crescimento e restauração dos tecidos animais. De acordo com Goodman (2003), o pólen contém proteínas, lipídios, incluindo esteróis, amido, 
açúcar, vários minerais e vitaminas. Almeida-Muradian et al. (2005) encontraram proteínas, lipídios, cinzas e carotenóides totais em bolotas de pólen apícola.

Apesar de haver uma provável relação entre a escolha da fonte de pólen, coletado pelas abelhas, e a disponibilidade de recursos, coloração, odor e morfologia das flores (Bhagavan \& Smith, 1997; Hill et al., 1997; Pernal \& Currie, 2002), a preferência de coleta pelas abelhas em razão da qualidade nutricional do pólen é ainda muito discutida (Pernal \& Currie, 2001; Roulston \& Cane, 2002; Cook et al., 2003).

Os tipos polínicos podem variar conforme a região ou época do ano em que estes são ofertados. Conhecer o valor nutricional dos diferentes tipos polínicos pode, portanto, contribuir para escolha do local de instalação de apiários e sugerir ingredientes para a produção de substitutos protéicos, em épocas de entressafra de pólen (Pereira et al., 2006). Para Almeida-Muradian et al. (2005), o conhecimento nutricional do pólen apícola pode ser utilizado no controle da qualidade deste produto, principalmente para direcionar a produção comercial do pólen monofloral, ou seja, proveniente de uma mesma espécie de planta.

O objetivo deste trabalho foi avaliar a influência das composições florísticas locais, sobre a qualidade do pólen apícola, e correlacionar os componentes nutricionais à diversidade e à qualidade dos tipos polínicos coletados pelas abelhas, em Minas Gerais.

\section{Material e Métodos}

$\mathrm{O}$ experimento foi conduzido em dois locais antropizados, com domínio de Mata Atlântica (floresta estacional semidecidual), em Viçosa, MG (22\%45'S e $42^{\circ} 52^{\prime} \mathrm{W}$ ), no apiário central da Universidade Federal de Viçosa (apiário UFV); e em Paula Cândido, MG (2049'S e 42054'W), no apiário Mesmel, no sítio Bom Jardim.

Todas as plantas observadas em floração, durante o período de estudo, nas proximidades do apiário UFV e do apiário Mesmel, foram coletadas e identificadas, e delas foi retirado pólen para a composição da coleção de referência de lâminas de microscopia. A determinação da flora polinífera foi realizada pela presença do tipo polínico das plantas nas bolotas de pólen coletadas pelas abelhas. A nomenclatura das espécies vegetais em floração, coletadas nos apiários, seguiu o sistema de Cronquist (1988), exceto para a família Leguminosae.
Para as coletas de pólen, foram selecionadas ao acaso, por apiário, cinco colméias do tipo Langstroth, com abelhas africanizadas (A. mellifera), e com um ninho para postura da rainha. Antes do início das coletas, as rainhas foram substituídas por rainhas novas, cujas linhagens não foram controladas. Cada colônia recebeu um coletor de pólen, tipo intermediário, instalado na parte superior da colméia.

As amostras foram obtidas em intervalos de duas semanas, durante o período de entressafra de mel, entre 12 de agosto e 13 de dezembro de 2005 no apiário UFV, e entre 15 de agosto e 23 de novembro de 2005 no apiário Mesmel. No final destes períodos, obtiveram-se oito amostras para cada apiário estudado. Para manter a integridade qualitativa, o pólen retido foi retirado dos coletores a cada 2-3 dias, limpado por catação, pesado em balança de precisão, separado por período de coleta, e armazenado em freezer entre -22 e $-14^{\circ} \mathrm{C}$ até o seu processamento.

De cada amostra homogeneizada foram separados, aproximadamente, $20 \mathrm{~g}$ de bolotas de pólen, o qual foi secado por 72 horas a cerca de $55^{\circ} \mathrm{C}$, em estufa de circulação forçada de ar (pré-secagem). Estas amostras foram enviadas ao Laboratório de Nutrição Animal, do Departamento de Zootecnia da UFV, para as análises físicoquímicas de rotina (Silva, 2002): porcentagem de matéria seca, matéria orgânica, matéria mineral, proteína bruta, extrato etéreo e carboidratos totais.

A preparação melissopalinológica das amostras de bolotas de pólen seguiu o método padrão europeu de Maurizio \& Louveaux (1965) para amostras de mel, sem uso da acetólise. Na análise qualitativa de cada amostra, todo tipo polínico observado pela primeira vez foi desenhado e descrito sumariamente. A identificação dos tipos polínicos foi baseada, principalmente, na coleção de referência de lâminas de microscopia com pólen das plantas floridas da região de estudo, assim como em catálogos especializados em morfologia polínica de espécies de diversas floras (SalgadoLabouriau, 1973; Melhem et al., 1984; Roubik \& Moreno, 1991). Foram identificados e contados aproximadamente 500 grãos de pólen por amostra.

O tipo polínico é designado pelo nome de um dos gêneros ou espécie que nele se inclui, que não está relacionado ao Código Internacional de Nomenclatura Botânica, e sim estabelece uma proximidade do material analisado a um determinado grupo taxonômico (Salgado-Labouriau, 1973; Lorscheitter, 1989).

As médias das análises físico-químicas do pólen dos dois apiários experimentais foram comparadas pelo teste $\mathrm{t}$ de 
Student. Análises de correlação de Spearman entre os tipos polínicos e os valores das análises físico-químicas foram realizadas.

Para o cálculo das frequiências do pólen, os tipos polínicos com média menor que $1 \%$ foram agrupados e denominados Outros, e os de média maior que $1 \%$ foram avaliados individualmente.

\section{Resultados e Discussão}

No apiário UFV, foi observada uma grande diversidade de espécies vegetais em floração possivelmente poliníferas, com habitat ornamental e hábito arbóreo, como Arecaceae sp., Bauhinia variegata L., Caesalpinia peltophoroides Benth., Callistemon sp., Erythrina falcata Benth., Grevillea robusta A. Cunn. ex R. Br., Joannesia princeps Vell., Lecythis pisonis Cambess., Michelia champaca L., Melia azedarach L., Spathodea campanulata P. Beauv., Stenolobium stans Seem. e Tabebuia roseoalba (Ridl.) Sandwith. No apiário Mesmel, ocorreram espécies vegetais oriundas, principalmente, de pastagem abandonada e com hábito herbáceo, como Bidens pilosa L., Emilia sagittata DC., Eupatorium sp., Lantana camara L., Leandra aurea Cogn., Solanum velleum Sw.ex Roem. \& Schult., Sonchus oleraceus L. e Vernonia lanuginosa Gardner.

Embora sejam diferentes as características florísticas, nas proximidades de ambos os apiários, as análises nutricionais do pólen coletado pelas abelhas, nos dois locais, apresentaram médias iguais ( $\mathrm{p}>0,05)$ (Tabela 1$)$.

No apiário Mesmel, ao longo das coletas, houve maior variabilidade nas características nutricionais do pólen coletado do que no apiário UFV (Tabela 1). Este resultado, possivelmente, está relacionado às características florais inerentes de cada apiário. As plantas ornamentais são mantidas por manejos técnicos, em floração durante longo período, e ao coletar nessas plantas, as abelhas mantêm um padrão qualitativo do pólen. Em área de pastagem abandonada, não há uniformidade nas espécies de plantas, e seu período de floração é curto em relação ao daquelas usadas para ornamentação, uma vez que não são induzidas a longos períodos de floração.

Tabela 1. Análises físico-químicas realizadas em bolotas de pólen, de colméias de abelhas Apis mellifera do apiário UFV, de 12 de agosto a 13 de dezembro de 2005, e do apiário Mesmel, de 15 de agosto a 23 de novembro de $2005^{(1)}$.

\begin{tabular}{|c|c|c|c|c|c|c|c|}
\hline $\begin{array}{l}\text { Período } \\
\text { de coleta }\end{array}$ & $\begin{array}{l}\text { Matéria } \\
\text { seca }\end{array}$ & Umidade & $\begin{array}{l}\text { Matéria } \\
\text { orgânica }\end{array}$ & $\begin{array}{l}\text { Matéria } \\
\text { mineral }\end{array}$ & $\begin{array}{l}\text { Proteína } \\
\text { bruta }\end{array}$ & $\begin{array}{l}\text { Extrato } \\
\text { etéreo }\end{array}$ & $\begin{array}{l}\text { Carboidratos } \\
\text { totais }\end{array}$ \\
\hline \multicolumn{8}{|c|}{ UFV } \\
\hline $12 / 8$ a $29 / 8$ & 74,37 & 25,63 & 97,98 & 2,02 & 22,73 & 4,32 & 70,93 \\
\hline $30 / 8$ a $11 / 9$ & 72,52 & 27,48 & 97,78 & 2,22 & 21,39 & 2,50 & 73,89 \\
\hline $12 / 9$ a $28 / 9$ & 73,41 & 26,59 & 97,52 & 2,48 & 24,06 & 1,84 & 71,62 \\
\hline $29 / 9$ a $10 / 10$ & 74,06 & 25,93 & 96,81 & 3,19 & 27,09 & 2,46 & 67,26 \\
\hline $11 / 10$ a $27 / 10$ & 74,43 & 25,57 & 97,47 & 2,53 & 28,51 & 2,55 & 66,41 \\
\hline $28 / 10$ a $07 / 11$ & 72,53 & 27,47 & 96,69 & 3,31 & 40,53 & 1,73 & 54,43 \\
\hline $08 / 11$ a $22 / 11$ & 72,22 & 27,78 & 96,33 & 3,67 & 29,16 & 2,42 & 64,75 \\
\hline $23 / 11$ a $13 / 12$ & 69,64 & 30,36 & 96,78 & 3,22 & 32,71 & 3,00 & 61,07 \\
\hline Média & $72,90 \pm 1,58 \mathrm{a}$ & $27,10 \pm 1,58 \mathrm{a}$ & $97,17 \pm 0,59 a$ & $2,83 \pm 0,59 a$ & $28,27 \pm 6,19 a$ & $2,60 \pm 0,80 \mathrm{a}$ & $66,30 \pm 6,31 \mathrm{a}$ \\
\hline $\mathrm{CV}(\%)$ & 2,17 & 5,83 & 0,60 & 20,85 & 21,89 & 30,77 & 9,52 \\
\hline \multicolumn{8}{|c|}{ Mesmel } \\
\hline $16 / 8$ & 72,57 & 27,43 & 98,57 & 1,43 & 15,79 & 5,56 & 77,22 \\
\hline $17 / 8$ a $31 / 8$ & 76,66 & 23,33 & 98,35 & 1,65 & 16,51 & 5,27 & 76,57 \\
\hline $01 / 9$ a $14 / 9$ & 79,25 & 20,75 & 97,65 & 2,35 & 19,71 & 2,61 & 75,33 \\
\hline $15 / 9$ a $28 / 9$ & 59,56 & 40,44 & 95,78 & 4,22 & 28,71 & 0,19 & 66,88 \\
\hline $29 / 9$ a $12 / 10$ & 72,08 & 27,91 & 95,71 & 4,29 & 28,52 & 1,01 & 66,18 \\
\hline $13 / 10$ a $27 / 10$ & 76,95 & 23,04 & 96,78 & 3,22 & 25,13 & 1,76 & 69,89 \\
\hline $28 / 10$ a $09 / 11$ & 71,58 & 28,42 & 95,94 & 4,06 & 31,69 & 0,95 & 63,30 \\
\hline $10 / 11$ a $23 / 11$ & 68,59 & 31,50 & 97,05 & 2,95 & 23,76 & 0,96 & 72,33 \\
\hline Média & $72,16 \pm 6,16 \mathrm{a}$ & $27,85 \pm 6,17 \mathrm{a}$ & $96,98 \pm 1,14 \mathrm{a}$ & $3,02 \pm 1,14 \mathrm{a}$ & $23,73 \pm 5,91 \mathrm{a}$ & $2,29 \pm 2,06 \mathrm{a}$ & $70,96 \pm 5,22 \mathrm{a}$ \\
\hline $\mathrm{CV}(\%)$ & 8,53 & 22,15 & 1,17 & 37,75 & 24,90 & 89,95 & 7,35 \\
\hline
\end{tabular}

${ }^{(1)}$ Médias seguidas por letras iguais, na coluna, não diferem entre si, pelo teste t, a 5\% de probabilidade. 
Os resultados das análises físico-químicas, neste estudo, estão de acordo com o regulamento técnico que estabelece os seguintes valores para a comercialização de pólen no Brasil: umidade máxima de $30 \%$, máximo de $4 \%$ de cinzas, extrato etéreo mínimo de $1,8 \%$ e proteína mínima de $8 \%$ (Brasil, 2001).

Os valores físico-químicos do pólen coletado por abelhas A. mellifera, neste trabalho, são próximos aos valores obtidos em trabalhos realizados na região Sudeste do Brasil (Funari et al., 2003; Barreto et al., 2005; Marchini et al., 2006), e aos obtidos com pólen de abelhas sem ferrão na região Amazônica (Souza et al., 2004).

No apiário UFV, os valores de matéria orgânica apresentaram correlação positiva com Baccharis,
Gochnatia e Vernonia e, apresentaram correlação negativa com Anadenanthera (Tabela 2).

Os valores de matéria seca apresentaram correlação positiva com a presença de Elephantopus e Trema (Tabela 2). Em concordância com estes resultados, a família Asteraceae, na qual se insere o tipo polínico Elephantopus, foi citada como de baixo teor de umidade média por Pernal \& Currie (2000) $(17,66 \%)$ e Pernal \& Currie (2001) (17,47\%).

A proteína bruta apresentou correlação positiva com a presença de Anadenanthera e Arecaceae 1, e correlação negativa com Baccharis, Gochnatia e Vernonia (Tabela 2). De maneira semelhante, espécies da família Asteraceae, na qual se inserem os tipos

Tabela 2. Correlação de Spearman entre componentes nutricionais e os tipos polínicos coletados em colméias de Apis mellifera, no apiário UFV, de agosto a dezembro de $2005^{(1)}$.

\begin{tabular}{|c|c|c|c|c|c|c|c|c|}
\hline Tipo polínico & Coeficiente & $\begin{array}{c}\text { Matéria } \\
\text { seca }\end{array}$ & Umidade & $\begin{array}{l}\text { Matéria } \\
\text { orgânica }\end{array}$ & Matéria & $\begin{array}{c}\text { Proteína } \\
\text { bruta }\end{array}$ & $\begin{array}{l}\text { Extrato } \\
\text { etéreo }\end{array}$ & $\begin{array}{c}\text { Carboidratos } \\
\text { totais }\end{array}$ \\
\hline Anacardiaceae & $\begin{array}{l}\mathrm{r}_{\mathrm{s}} \\
\mathrm{p}\end{array}$ & $\begin{array}{l}0,571 \\
0,139\end{array}$ & $\begin{array}{r}-0,571 \\
0,139\end{array}$ & $\begin{array}{l}0,238 \\
0,570\end{array}$ & $\begin{array}{r}-0,238 \\
0,570\end{array}$ & $\begin{array}{r}-0,024 \\
0,955\end{array}$ & $\begin{array}{r}-0,310 \\
0,456\end{array}$ & $\begin{array}{l}0,095 \\
0,823\end{array}$ \\
\hline Anadenanthera & $\begin{array}{l}r_{s} \\
\mathrm{p}\end{array}$ & $\begin{array}{r}-0,444 \\
0,271 \\
\end{array}$ & $\begin{array}{l}0,444 \\
0,271\end{array}$ & $\begin{array}{c}-0,850 \\
0,008^{* *}\end{array}$ & $\begin{array}{l}0,850 \\
0,008 * *\end{array}$ & $\begin{array}{l}0,913 \\
0,002 * *\end{array}$ & $\begin{array}{r}-0,342 \\
0,406 \\
\end{array}$ & $\begin{array}{c}-0,913 \\
0,002 * *\end{array}$ \\
\hline Arecaceae 1 & $\begin{array}{l}\mathrm{r}_{\mathrm{s}} \\
\mathrm{p}\end{array}$ & $\begin{array}{r}-0,467 \\
0,243 \\
\end{array}$ & $\begin{array}{l}0,467 \\
0,243 \\
\end{array}$ & $\begin{array}{r}-0,635 \\
0,091 \\
\end{array}$ & $\begin{array}{l}0,635 \\
0,091\end{array}$ & $\begin{array}{l}0,707 \\
0,050^{*}\end{array}$ & $\begin{array}{l}0,012 \\
0,978\end{array}$ & $\begin{array}{c}-0,755 \\
0,031^{*}\end{array}$ \\
\hline Baccharis & $\begin{array}{l}r_{\mathrm{s}} \\
\mathrm{p}\end{array}$ & $\begin{array}{l}0,055 \\
0,898 \\
\end{array}$ & $\begin{array}{r}-0,055 \\
0,898 \\
\end{array}$ & $\begin{array}{l}0,791 \\
0,019^{*}\end{array}$ & $\begin{array}{c}-0,791 \\
0,019^{*}\end{array}$ & $\begin{array}{c}-0,846 \\
0,008 * *\end{array}$ & $\begin{array}{l}0,082 \\
0,847 \\
\end{array}$ & $\begin{array}{l}0,873 \\
0,005^{* *}\end{array}$ \\
\hline Cecropia & $\begin{array}{l}r_{s} \\
\mathrm{p}\end{array}$ & $\begin{array}{r}-0,436 \\
0,280 \\
\end{array}$ & $\begin{array}{l}0,436 \\
0,280\end{array}$ & $\begin{array}{r}-0,047 \\
0,912\end{array}$ & $\begin{array}{l}0,047 \\
0,912 \\
\end{array}$ & $\begin{array}{l}0,187 \\
0,657 \\
\end{array}$ & $\begin{array}{l}0,078 \\
0,854\end{array}$ & $\begin{array}{r}-0,078 \\
0,854\end{array}$ \\
\hline Coffea & $\begin{array}{l}\mathrm{r}_{\mathrm{s}} \\
\mathrm{p}\end{array}$ & $\begin{array}{l}0,013 \\
0,976 \\
\end{array}$ & $\begin{array}{r}-0,013 \\
0,976 \\
\end{array}$ & $\begin{array}{r}-0,393 \\
0,335 \\
\end{array}$ & $\begin{array}{l}0,393 \\
0,335 \\
\end{array}$ & $\begin{array}{l}0,152 \\
0,719 \\
\end{array}$ & $\begin{array}{r}-0,178 \\
0,674 \\
\end{array}$ & $\begin{array}{r}-0,241 \\
0,565 \\
\end{array}$ \\
\hline Elephantopus & $\begin{array}{l}\mathrm{r}_{\mathrm{s}} \\
\mathrm{p}\end{array}$ & $\begin{array}{l}0,731 \\
0,040^{*}\end{array}$ & $\begin{array}{c}-0,731 \\
0,040 * \\
\end{array}$ & $\begin{array}{l}0,359 \\
0,382 \\
\end{array}$ & $\begin{array}{r}-0,359 \\
0,382 \\
\end{array}$ & $\begin{array}{r}-0,323 \\
0,435 \\
\end{array}$ & $\begin{array}{r}-0,144 \\
0,734 \\
\end{array}$ & $\begin{array}{l}0,395 \\
0,333 \\
\end{array}$ \\
\hline Eucalyptus & $\begin{array}{l}r_{s} \\
\mathrm{p}\end{array}$ & $\begin{array}{l}0,409 \\
0,314\end{array}$ & $\begin{array}{r}-0,409 \\
0,314\end{array}$ & $\begin{array}{l}0,436 \\
0,280\end{array}$ & $\begin{array}{r}-0,436 \\
0,280 \\
\end{array}$ & $\begin{array}{r}-0,382 \\
0,351\end{array}$ & $\begin{array}{r}-0,027 \\
0,949 \\
\end{array}$ & $\begin{array}{l}0,491 \\
0,217\end{array}$ \\
\hline Euphorbiaceae & $\begin{array}{l}\mathrm{r}_{\mathrm{s}} \\
\mathrm{p}\end{array}$ & $\begin{array}{l}0,073 \\
0,863 \\
\end{array}$ & $\begin{array}{r}-0,073 \\
0,863 \\
\end{array}$ & $\begin{array}{l}0,415 \\
0,307 \\
\end{array}$ & $\begin{array}{r}-0,415 \\
0,307 \\
\end{array}$ & $\begin{array}{r}-0,464 \\
0,247 \\
\end{array}$ & $\begin{array}{r}-0,512 \\
0,194 \\
\end{array}$ & $\begin{array}{l}0,561 \\
0,148 \\
\end{array}$ \\
\hline Gochnatia & $\begin{array}{l}r_{s} \\
\mathrm{p}\end{array}$ & $\begin{array}{l}0,187 \\
0,657 \\
\end{array}$ & $\begin{array}{r}-0,187 \\
0,657 \\
\end{array}$ & $\begin{array}{l}0,764 \\
0,027 * \\
\end{array}$ & $\begin{array}{c}-0,764 \\
0,027^{*} \\
\end{array}$ & $\begin{array}{c}-0,733 \\
0,039 * \\
\end{array}$ & $\begin{array}{l}0,546 \\
0,162 \\
\end{array}$ & $\begin{array}{l}0,592 \\
0,122 \\
\end{array}$ \\
\hline Myrcia & $\begin{array}{l}r_{s} \\
\mathrm{p}\end{array}$ & $\begin{array}{r}-0,122 \\
0,774 \\
\end{array}$ & $\begin{array}{l}0,122 \\
0,774 \\
\end{array}$ & $\begin{array}{r}-0,268 \\
0,520 \\
\end{array}$ & $\begin{array}{l}0,268 \\
0,520 \\
\end{array}$ & $\begin{array}{l}0,317 \\
0,444 \\
\end{array}$ & $\begin{array}{l}0,244 \\
0,560 \\
\end{array}$ & $\begin{array}{r}-0,415 \\
0,307 \\
\end{array}$ \\
\hline Ricinus & $\begin{array}{l}\mathrm{r}_{\mathrm{s}} \\
\mathrm{p}\end{array}$ & $\begin{array}{l}0,464 \\
0,247 \\
\end{array}$ & $\begin{array}{r}-0,464 \\
0,247 \\
\end{array}$ & $\begin{array}{r}-0,171 \\
0,686 \\
\end{array}$ & $\begin{array}{l}0,171 \\
0,686 \\
\end{array}$ & $\begin{array}{l}0,342 \\
0,408 \\
\end{array}$ & $\begin{array}{r}-0,073 \\
0,863 \\
\end{array}$ & $\begin{array}{r}-0,464 \\
0,247 \\
\end{array}$ \\
\hline Senecio & $\begin{array}{l}r_{s} \\
\mathrm{p}\end{array}$ & $\begin{array}{r}-0,690 \\
0,058 \\
\end{array}$ & $\begin{array}{l}0,690 \\
0,058 \\
\end{array}$ & $\begin{array}{r}-0,571 \\
0,139 \\
\end{array}$ & $\begin{array}{l}0,571 \\
0,139 \\
\end{array}$ & $\begin{array}{l}0,571 \\
0,139 \\
\end{array}$ & $\begin{array}{r}-0,476 \\
0,233 \\
\end{array}$ & $\begin{array}{r}-0,429 \\
0,289 \\
\end{array}$ \\
\hline Trema & $\begin{array}{l}\mathrm{r}_{\mathrm{s}} \\
\mathrm{p}\end{array}$ & $\begin{array}{l}0,764 \\
0,027 *\end{array}$ & $\begin{array}{c}-0,764 \\
0,027 *\end{array}$ & $\begin{array}{l}0,452 \\
0,261\end{array}$ & $\begin{array}{r}-0,452 \\
0,261\end{array}$ & $\begin{array}{r}-0,203 \\
0,630\end{array}$ & $\begin{array}{l}0,592 \\
0,122 \\
\end{array}$ & $\begin{array}{l}0,094 \\
0,826\end{array}$ \\
\hline Vernonia & $\begin{array}{l}\mathrm{r}_{\mathrm{s}} \\
\mathrm{p}\end{array}$ & $\begin{array}{l}0,599 \\
0,117 \\
\end{array}$ & $\begin{array}{r}-0,599 \\
0,117 \\
\end{array}$ & $\begin{array}{l}0,731 \\
0,040 *\end{array}$ & $\begin{array}{c}-0,731 \\
0,040^{*}\end{array}$ & $\begin{array}{c}-0,743 \\
0,035^{*} \\
\end{array}$ & $\begin{array}{l}0,503 \\
0,204 \\
\end{array}$ & $\begin{array}{l}0,671 \\
0,069 \\
\end{array}$ \\
\hline Outros & $\begin{array}{l}r_{s} \\
p\end{array}$ & $\begin{array}{r}-0,452 \\
0,260\end{array}$ & $\begin{array}{l}0,452 \\
0,260\end{array}$ & $\begin{array}{r}-0,405 \\
0,320\end{array}$ & $\begin{array}{l}0,405 \\
0,320\end{array}$ & $\begin{array}{l}0,405 \\
0,320\end{array}$ & $\begin{array}{r}-0,333 \\
0,420\end{array}$ & $\begin{array}{r}-0,238 \\
0,570\end{array}$ \\
\hline
\end{tabular}

${ }^{(1)} \mathrm{N}=8 ; \mathrm{r}_{\mathrm{s}}$ : coeficiente de correlação de postos de Spearman; p: probabilidade associada ao teste. * e **Significativo a 5 e $1 \%$ de probabilidade. 
polínicos Baccharis, Gochnatia e Vernonia, apresentaram baixo valor protéico em estudos realizados por Pernal \& Currie (2000) $(14,86 \%)$ e Pernal \& Currie (2001) (14,95\%). Um índice protéico elevado também foi encontrado para a família de Anadenanthera (Leguminosae) por Pernal \& Currie (2000) $(24,15 \%)$ e Pernal \& Currie (2001) (24,21\%). De acordo com Roulston et al. (2000), os grãos de pólen apresentam concentração protéica de 2,5 a $61 \%$. De acordo com esses autores, a variação protéica não pode ser diretamente relacionada com a atratividade de polinizadores, uma vez que o pólen das espécies zoófilas não é mais rico em proteínas do que o das espécies anemófilas.

Os valores do extrato etéreo, no apiário UFV, não apresentaram correlação com nenhuma ocorrência de tipos polínicos específicos ( $\mathrm{p}>0,05)$ (Tabela 2). Os valores de carboidratos totais apresentaram correlação positiva com Baccharis e correlação negativa com Anadenanthera e Arecaceae 1.

No apiário Mesmel, os valores da matéria seca apresentaram correlação positiva com Araceae (Tabela 3). No entanto, as diferentes concentrações de umidade no pólen predominante, em determinados

Tabela 3. Correlação de Spearman entre componentes nutricionais e tipos polínicos coletados em colméias de Apis mellifera, no apiário Mesmel, de agosto a novembro de $2005^{(1)}$.

\begin{tabular}{|c|c|c|c|c|c|c|c|c|}
\hline Tipo polínico & Coeficiente & $\begin{array}{c}\text { Matéria } \\
\text { seca }\end{array}$ & Umidade & $\begin{array}{l}\text { Matéria } \\
\text { orgânica }\end{array}$ & $\begin{array}{l}\text { Matéria } \\
\text { mineral }\end{array}$ & $\begin{array}{l}\text { Proteína } \\
\text { bruta }\end{array}$ & $\begin{array}{l}\text { Extrato } \\
\text { etéreo }\end{array}$ & $\begin{array}{c}\text { Carboidratos } \\
\text { totais }\end{array}$ \\
\hline Alchornea & $\begin{array}{l}\mathrm{r}_{\mathrm{s}} \\
\mathrm{p}\end{array}$ & $\begin{array}{r}-0,412 \\
0,310 \\
\end{array}$ & $\begin{array}{l}0,412 \\
0,310 \\
\end{array}$ & $\begin{array}{l}0,082 \\
0,846 \\
\end{array}$ & $\begin{array}{r}-0,082 \\
0,846 \\
\end{array}$ & $\begin{array}{r}-0,082 \\
0,846 \\
\end{array}$ & $\begin{array}{r}-0,247 \\
0,555 \\
\end{array}$ & $\begin{array}{l}0,082 \\
0,846 \\
\end{array}$ \\
\hline Anacardiaceae & $\begin{array}{l}r_{s} \\
p\end{array}$ & $\begin{array}{r}-0,082 \\
0,847 \\
\end{array}$ & $\begin{array}{l}0,082 \\
0,847 \\
\end{array}$ & $\begin{array}{r}-0,627 \\
0,096 \\
\end{array}$ & $\begin{array}{l}0,627 \\
0,096 \\
\end{array}$ & $\begin{array}{l}0,464 \\
0,247 \\
\end{array}$ & $\begin{array}{r}-0,355 \\
0,389 \\
\end{array}$ & $\begin{array}{r}-0,436 \\
0,280 \\
\end{array}$ \\
\hline Anadenanthera & $\begin{array}{l}r_{s} \\
p\end{array}$ & $\begin{array}{r}-0,136 \\
0,747 \\
\end{array}$ & $\begin{array}{l}0,136 \\
0,747 \\
\end{array}$ & $\begin{array}{r}-0,218 \\
0,604 \\
\end{array}$ & $\begin{array}{l}0,218 \\
0,604 \\
\end{array}$ & $\begin{array}{l}0,491 \\
0,217 \\
\end{array}$ & $\begin{array}{r}-0,409 \\
0,314 \\
\end{array}$ & $\begin{array}{r}-0,491 \\
0,217 \\
\end{array}$ \\
\hline Arecaceae 3 & $\begin{array}{l}r_{s} \\
p\end{array}$ & $\begin{array}{r}-0,082 \\
0,846 \\
\end{array}$ & $\begin{array}{l}0,082 \\
0,846 \\
\end{array}$ & $\begin{array}{r}-0,577 \\
0,134 \\
\end{array}$ & $\begin{array}{l}0,577 \\
0,134 \\
\end{array}$ & $\begin{array}{l}0,247 \\
0,555 \\
\end{array}$ & $\begin{array}{r}-0,082 \\
0,846 \\
\end{array}$ & $\begin{array}{r}-0,412 \\
0,310 \\
\end{array}$ \\
\hline Araceae & $\begin{array}{l}r_{s} \\
p\end{array}$ & $\begin{array}{l}0,723 \\
0,043^{*}\end{array}$ & $\begin{array}{c}-0,723 \\
0,043^{*}\end{array}$ & $\begin{array}{l}0,000 \\
1,000\end{array}$ & $\begin{array}{l}0,000 \\
1,000\end{array}$ & $\begin{array}{r}-0,228 \\
0,587 \\
\end{array}$ & $\begin{array}{l}0,406 \\
0,318\end{array}$ & $\begin{array}{l}0,114 \\
0,788\end{array}$ \\
\hline Baccharis & $\begin{array}{l}r_{s} \\
p\end{array}$ & $\begin{array}{l}0,655 \\
0,078\end{array}$ & $\begin{array}{r}-0,655 \\
0,078\end{array}$ & $\begin{array}{l}0,483 \\
0,225\end{array}$ & $\begin{array}{r}-0,483 \\
0,225 \\
\end{array}$ & $\begin{array}{r}-0,483 \\
0,225\end{array}$ & $\begin{array}{l}0,483 \\
0,225\end{array}$ & $\begin{array}{l}0,483 \\
0,225\end{array}$ \\
\hline Cecropia & $\begin{array}{l}r_{s} \\
p\end{array}$ & $\begin{array}{l}0,299 \\
0,471 \\
\end{array}$ & $\begin{array}{r}-0,299 \\
0,471 \\
\end{array}$ & $\begin{array}{l}0,838 \\
0,009 * * \\
\end{array}$ & $\begin{array}{c}-0,838 \\
0,009^{* *}\end{array}$ & $\begin{array}{c}-0,838 \\
0,009 * * \\
\end{array}$ & $\begin{array}{l}0,671 \\
0,069 \\
\end{array}$ & $\begin{array}{l}0,922 \\
0,001 * * \\
\end{array}$ \\
\hline Citrus & $\begin{array}{l}r_{s} \\
p\end{array}$ & $\begin{array}{l}0,577 \\
0,134\end{array}$ & $\begin{array}{r}-0,577 \\
0,134 \\
\end{array}$ & $\begin{array}{l}0,247 \\
0,555\end{array}$ & $\begin{array}{r}-0,247 \\
0,555 \\
\end{array}$ & $\begin{array}{r}-0,247 \\
0,555\end{array}$ & $\begin{array}{l}0,247 \\
0,555\end{array}$ & $\begin{array}{l}0,247 \\
0,555\end{array}$ \\
\hline Coffea & $\begin{array}{l}r_{s} \\
p\end{array}$ & $\begin{array}{r}-0,610 \\
0,108 \\
\end{array}$ & $\begin{array}{l}0,610 \\
0,108 \\
\end{array}$ & $\begin{array}{c}-0,732 \\
0,039^{*}\end{array}$ & $\begin{array}{l}0,732 \\
0,039^{*}\end{array}$ & $\begin{array}{l}0,683 \\
0,062 \\
\end{array}$ & $\begin{array}{r}-0,610 \\
0,108 \\
\end{array}$ & $\begin{array}{c}-0,732 \\
0,039^{*}\end{array}$ \\
\hline Eucalyptus & $\begin{array}{l}r_{s} \\
p\end{array}$ & $\begin{array}{l}0,076 \\
0,858 \\
\end{array}$ & $\begin{array}{r}-0,076 \\
0,858 \\
\end{array}$ & $\begin{array}{l}0,266 \\
0,524 \\
\end{array}$ & $\begin{array}{r}-0,266 \\
0,524 \\
\end{array}$ & $\begin{array}{r}-0,266 \\
0,524 \\
\end{array}$ & $\begin{array}{l}0,127 \\
0,765 \\
\end{array}$ & $\begin{array}{l}0,406 \\
0,318 \\
\end{array}$ \\
\hline Gochnatia & $\begin{array}{l}r_{s} \\
p\end{array}$ & $\begin{array}{l}0,655 \\
0,078 \\
\end{array}$ & $\begin{array}{r}-0,655 \\
0,078 \\
\end{array}$ & $\begin{array}{l}0,483 \\
0,225 \\
\end{array}$ & $\begin{array}{r}-0,483 \\
0,225 \\
\end{array}$ & $\begin{array}{r}-0,483 \\
0,225 \\
\end{array}$ & $\begin{array}{l}0,483 \\
0,225 \\
\end{array}$ & $\begin{array}{l}0,483 \\
0,225 \\
\end{array}$ \\
\hline Myrcia & $\begin{array}{l}r_{s} \\
p\end{array}$ & $\begin{array}{r}-0,025 \\
0,952 \\
\end{array}$ & $\begin{array}{l}0,025 \\
0,952 \\
\end{array}$ & $\begin{array}{r}-0,520 \\
0,186 \\
\end{array}$ & $\begin{array}{l}0,520 \\
0,186 \\
\end{array}$ & $\begin{array}{l}0,571 \\
0,140 \\
\end{array}$ & $\begin{array}{r}-0,355 \\
0,388 \\
\end{array}$ & $\begin{array}{r}-0,660 \\
0,075 \\
\end{array}$ \\
\hline Piper & $\begin{array}{l}r_{s} \\
p\end{array}$ & $\begin{array}{l}0,187 \\
0,657 \\
\end{array}$ & $\begin{array}{r}-0,187 \\
0,657 \\
\end{array}$ & $\begin{array}{r}-0,234 \\
0,577 \\
\end{array}$ & $\begin{array}{l}0,234 \\
0,577 \\
\end{array}$ & $\begin{array}{l}0,452 \\
0,261 \\
\end{array}$ & $\begin{array}{r}-0,203 \\
0,630 \\
\end{array}$ & $\begin{array}{r}-0,452 \\
0,261 \\
\end{array}$ \\
\hline Scrophulariaceae & $\begin{array}{l}r_{s} \\
p\end{array}$ & $\begin{array}{l}0,627 \\
0,096 \\
\end{array}$ & $\begin{array}{r}-0,627 \\
0,096 \\
\end{array}$ & $\begin{array}{l}0,791 \\
0,019 *\end{array}$ & $\begin{array}{c}-0,791 \\
0,019 * \\
\end{array}$ & $\begin{array}{c}-0,791 \\
0,019 * \\
\end{array}$ & $\begin{array}{l}0,791 \\
0,019 *\end{array}$ & $\begin{array}{l}0,791 \\
0,019^{*}\end{array}$ \\
\hline Senecio & $\begin{array}{l}r_{s} \\
p\end{array}$ & $\begin{array}{l}0,310 \\
0,456 \\
\end{array}$ & $\begin{array}{r}-0,310 \\
0,456 \\
\end{array}$ & $\begin{array}{l}0,071 \\
0,867 \\
\end{array}$ & $\begin{array}{r}-0,071 \\
0,867 \\
\end{array}$ & $\begin{array}{l}0,024 \\
0,955 \\
\end{array}$ & $\begin{array}{r}-0,119 \\
0,779 \\
\end{array}$ & $\begin{array}{l}0,095 \\
0,823 \\
\end{array}$ \\
\hline Vernonia & $\begin{array}{l}r_{s} \\
p\end{array}$ & $\begin{array}{l}0,443 \\
0,272 \\
\end{array}$ & $\begin{array}{r}-0,443 \\
0,272 \\
\end{array}$ & $\begin{array}{l}0,575 \\
0,136 \\
\end{array}$ & $\begin{array}{r}-0,575 \\
0,136 \\
\end{array}$ & $\begin{array}{r}-0,647 \\
0,083 \\
\end{array}$ & $\begin{array}{l}0,707 \\
0,050 * \\
\end{array}$ & $\begin{array}{l}0,695 \\
0,056 \\
\end{array}$ \\
\hline Outros & $\begin{array}{l}r_{s} \\
p\end{array}$ & $\begin{array}{l}0,214 \\
0,610\end{array}$ & $\begin{array}{r}-0,214 \\
0,610\end{array}$ & $\begin{array}{r}-0,190 \\
0,651\end{array}$ & $\begin{array}{l}0,190 \\
0,651\end{array}$ & $\begin{array}{l}0,286 \\
0,493\end{array}$ & $\begin{array}{r}-0,333 \\
0,420\end{array}$ & $\begin{array}{r}-0,190 \\
0,651\end{array}$ \\
\hline
\end{tabular}

${ }^{(1)} \mathrm{N}=8 ; \mathrm{r}_{\mathrm{s}}$ : coeficiente de correlação de postos de Spearman; p: probabilidade associada ao teste. ${ }^{*}$ e ${ }^{* *}$ Significativo a 5 e $1 \%$ de probabilidade. 
períodos da coleta, podem ter ocorrido em consequiência das características botânicas das plantas poliníferas, e das condições atmosféricas durante o período da coleta e manuseio do pólen (Silveira, 1991; Garcia-Garcia et al., 2004).

Os valores de matéria orgânica apresentaram correlação positiva com Cecropia e Scrophulariaceae e correlação negativa com Coffea (Tabela 3). O extrato etéreo apresentou correlação positiva com
Scrophulariaceae e Vernonia. Os carboidratos totais apresentaram correlação positiva com Cecropia e Scrophulariaceae e correlação negativa com Coffea. A proteína bruta esteve correlacionada negativamente com Cecropia e Scrophulariaceae.

A contagem dos tipos polínicos foi realizada considerando-se o número absoluto de grãos de pólen existentes nas lâminas de microscopia (Figura 1). Para a avaliação da viabilidade da produção comercial do pólen
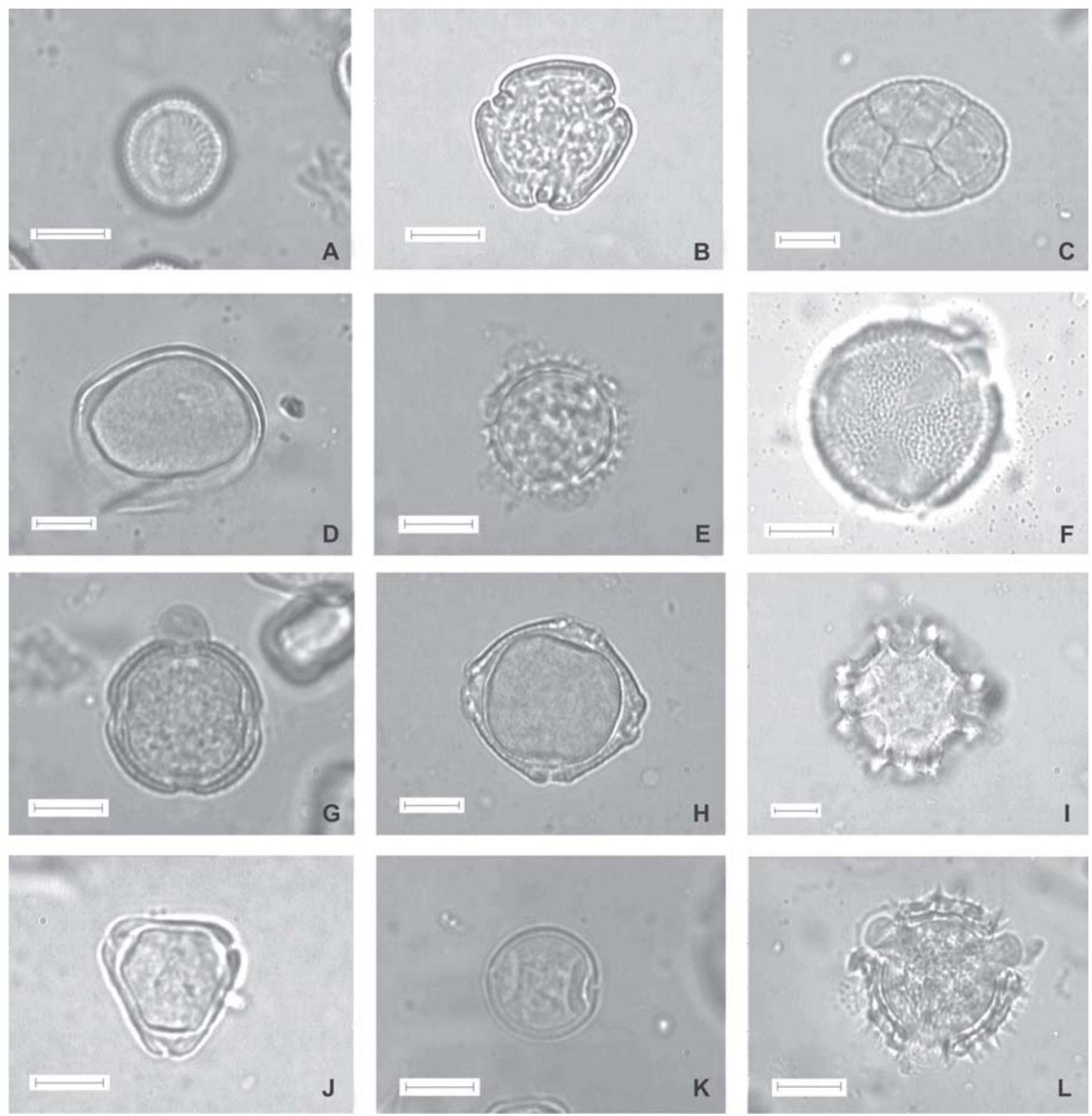

Figura 1. Fotomicrografias em microscopia óptica de grãos de pólen, observados nas amostras de bolotas de pólen de Apis mellifera, coletadas das colméias dos apiários Mesmel e UFV. A: Anacardiaceae; B: Alchornea; C: Anadenanthera; D: Arecaceae tipo 1; E: Baccharis; F: Bignoniaceae; G: Citrus; H: Coffea; I: Elephanthopus; $\mathrm{J}$ : Eucalyptus; K: Trema; L: Vernonia. Escalas nas figuras $=10 \mu \mathrm{m}$. 
coletado, deve-se, também, levar em consideração a densidade do pólen, medido em peso e em tamanho. Tipos de Cecropia apareceram com freqüência elevada $(18,98 \%)$, nas amostras do apiário Mesmel (Tabela 4), e são grãos de pólen diminutos (diâmetro polar e diâmetro equatorial em torno de $13 \times 9 \mu \mathrm{m}$ ) (Melhem et al., 2003). Assim, poucas bolotas deste tipo polínico podem causar sua super representação nas lâminas de microscopia. Tipos polínicos como Anadenanthera, com diâmetro polar e diâmetro equatorial em torno de 49x36,3 $\mu \mathrm{m}$ (Silvestre-Capelato \& Melhem, 1997), são maiores e, por este motivo, podem ter sua ocorrência sub-representada nas amostras (Tabelas 4 e 5). Sugere-se, portanto, a realização de estudos com objetivo de adaptar as técnicas palinológicas aos interesses comerciais da atividade apícola, como também sugerido por Castagnino et al. (2004).

Não houve correlação entre a diversidade de tipos polínicos e as variáveis carboidratos totais, extrato etéreo, matéria mineral, matéria orgânica, proteína bruta e matéria seca $(p>0,05)$. No entanto, os valores obtidos na análise nutricional do pólen coletado apresentaram correlações com a predominância de tipos polínicos específicos (Tabelas 2 e 3). De acordo com Schimdt \& Buchmann (1993), as abelhas de uma colônia coletam pólen em várias espécies de plantas e, assim, apresentam bom balanço nutricional e alta diluição da potencialidade tóxica de alcalóides e outras toxinas. Conforme os autores, as abelhas que foram tratadas com diferentes tipos de pólen sobreviveram durante mais tempo do que as abelhas tratadas com pólen de apenas uma espécie de planta. Portanto, é importante para as abelhas a coleta em diversas fontes, para a obtenção de uma dieta equilibrada.

Estudos sobre a preferência de A. mellifera pelo pólen rico em determinados componentes nutricionais, necessários para uma dieta equilibrada, apresentam resultados diversos. De acordo com Roulston \& Cane (2002), fatores controlados (quantidade de provisão) e fatores não controlados (qualidade de pólen) influenciam no comportamento forrageiro de abelhas. De acordo com Cook et al. (2003), uma determinada planta é mais visitada pelas abelhas A. mellifera, em razão do maior número de aminoácidos essenciais que ela possui. Para Gary (1993), os nutrientes de determinada flora são solicitados pela colônia, possivelmente, por causa das influências evolutivas no comportamento forrageiro das abelhas e, por isso, são procurados por elas.

Tabela 4. Freqüência relativa dos tipos polínicos identificados nas bolotas de pólen coletadas por Apis mellifera no apiário Mesmel, de agosto a novembro de 2005.

\begin{tabular}{|c|c|c|c|c|c|c|c|c|}
\hline \multirow[t]{2}{*}{ Tipo polínico } & \multicolumn{8}{|c|}{ Datas de coleta } \\
\hline & $16 / 8$ & $17 / 8-31 / 8$ & $1 / 9-14 / 9$ & $15 / 9-28 / 9$ & 29/9-12/10 & 13/10-27/10 & 28/10-9/11 & $10 / 11-23 / 11$ \\
\hline Alchornea & -(1) & - & - & - & - & - & - & 66,74 \\
\hline Anacardiaceae & - & - & - & 1,83 & 0,35 & 20,40 & - & - \\
\hline Anadenanthera & - & - & - & - & - & 1,07 & 11,52 & 0,22 \\
\hline Arecaceae 3 & - & - & - & - & 1,73 & - & - & - \\
\hline Araceae & - & 0,19 & 2,34 & - & 1,90 & 0,18 & - & - \\
\hline Baccharis & - & 13,62 & 39,09 & - & - & - & - & - \\
\hline Cecropia & 51,99 & 29,18 & 28,82 & 21,57 & - & 1,62 & - & 18,67 \\
\hline Citrus & - & - & 1,09 & - & - & - & - & - \\
\hline Coffea & - & 6,81 & - & 55,21 & 80,83 & - & 61,42 & 4,72 \\
\hline Eucalyptus & 0,19 & 0,19 & 2,80 & 10,24 & - & - & - & - \\
\hline Gochnatia & - & 0,19 & 6,70 & - & - & - & - & - \\
\hline Myrcia & - & - & - & - & 13,64 & 30,23 & 15,35 & 4,72 \\
\hline Piper & - & - & - & - & - & 25,04 & 9,98 & - \\
\hline Scrophulariaceae & 0,57 & 2,14 & 1,87 & - & - & - & - & - \\
\hline Senecio & 0,76 & 1,75 & 11,68 & 8,04 & 0,69 & 12,16 & 0,77 & 3,43 \\
\hline Vernonia & 46,49 & 45,53 & 0,78 & 0,91 & 0,69 & 1,97 & - & - \\
\hline Outros & - & 0,40 & 4,83 & 2,20 & 0,17 & 7,33 & 0,96 & 1,50 \\
\hline Total & 100 & 100 & 100 & 100 & 100 & 100 & 100 & 100 \\
\hline
\end{tabular}

${ }^{(1)}$ Tipos polínicos não coletados na data. 
Tabela 5. Freqüência relativa dos tipos polínicos identificados nas bolotas de pólen coletadas por Apis mellifera no apiário UFV, de agosto a dezembro de 2005.

\begin{tabular}{|c|c|c|c|c|c|c|c|c|}
\hline \multirow[t]{2}{*}{ Tipo polínico } & \multicolumn{8}{|c|}{ Datas de coleta } \\
\hline & $12 / 8-29 / 8$ & $30 / 8-11 / 9$ & $12 / 9-28 / 9$ & $29 / 9-10 / 10$ & $11 / 10-27 / 10$ & $28 / 10-7 / 11$ & $8 / 11-22 / 11$ & $23 / 11-13 / 12$ \\
\hline Anacardiaceae & 1,69 & 3,61 & 4,77 & 2,15 & 15,03 & 14,79 & -(1) & 0,41 \\
\hline Anadenanthera & - & - & - & - & 1,50 & 50,63 & 15,30 & 12,37 \\
\hline Arecaceae 1 & 0,94 & - & 0,18 & - & 0,50 & 2,50 & 30,62 & 22,47 \\
\hline Arecaceae 2 & - & - & - & - & - & - & 5,37 & - \\
\hline Baccharis & 30,32 & 77,96 & 56,33 & - & - & - & - & - \\
\hline Bignoniaceae & - & - & - & - & - & - & 11,93 & - \\
\hline Cecropia & - & - & 1,65 & - & - & - & - & 2,47 \\
\hline Coffea & 1,70 & - & - & 7,24 & - & 1,04 & 33,00 & - \\
\hline Elephantopus & 0,56 & 1,40 & 1,47 & 1,76 & 6,00 & 0,63 & - & - \\
\hline Eucalyptus & - & 4,41 & 17,61 & - & 21,04 & - & - & - \\
\hline Euphorbiaceae & 0,20 & 7,62 & 8,44 & 0,98 & - & 1,04 & - & - \\
\hline Gochnatia & 3,20 & 1,60 & - & - & - & - & - & - \\
\hline Myrcia & 32,02 & - & - & 57,14 & - & 22,08 & 0,20 & 39,39 \\
\hline Ricinus & 2,45 & - & - & 0,20 & 1,17 & 5,20 & 0,20 & - \\
\hline Scrophulariaceae & 14,12 & - & - & - & - & - & - & - \\
\hline Senecio & - & 0,20 & 1,47 & 0,40 & 0,17 & 0,42 & 0,40 & 13,81 \\
\hline Tabebuia & - & - & - & - & - & - & - & 3,51 \\
\hline Trema & 0,56 & - & - & - & 51,25 & - & - & - \\
\hline Vernonia & 12,24 & 1,60 & 1,28 & 29,35 & 1,50 & - & - & 1,03 \\
\hline Outros & - & 1,60 & 6,80 & 0,78 & 1,84 & 1,67 & 2,98 & 4,54 \\
\hline Total & 100 & 100 & 100 & 100 & 100 & 100 & 100 & 100 \\
\hline
\end{tabular}

${ }^{(1)}$ Tipos polínicos não coletados na data.

\section{Conclusões}

1. As diferentes composições florísticas locais influenciam na qualidade do pólen apícola.

2. Os componentes nutricionais avaliados se correlacionam com a freqüência de tipos polínicos específicos e indicam a importância da coleta pelas abelhas Apis mellifera, em diversas fontes de pólen, para a obtenção de uma dieta mais rica e equilibrada.

3. A diversidade de tipos polínicos coletados pelas abelhas não influencia na composição nutricional do pólen apícola.

\section{Agradecimentos}

A Ângela Maria da Silva Corrêa, do Instituto de Botânica (SP), pelo auxílio nas identificações polínicas e fotomicrografias; ao Sr. Geraldo Neri Ferreira, do Apiário Central da UFV, pelo manejo das colméias; à Capes, por concessão de bolsa.

\section{Referências}

ALMEIDA-MURADIAN, L.B.; PAMPLONA, L.C.; COIMBRA, S.; BARTH, O.M. Chemical composition and botanical evaluation of dried bee pollen pellets. Journal of Food Composition and Analysis, v.18, p.105-111, 2005.

BARRETO, L.M.R.C.; FUNARI, S.R.C.; ORSI, R.O. Composição e qualidade do pólen apícola proveniente de sete estados brasileiros e do Distrito Federal. Boletim da Indústria Animal, v.62, p.167-175, 2005.

BHAGAVAN, S.; SMITH, B.H. Olfactory conditioning in the honey bee, Apis mellifera: affects of odor intensity. Physiology \& Behavior, v.61, p.107-117, 1997.

BRASIL. Instrução Normativa n.3 de 2001: Regulamento Técnico para Fixação de Identidade e Qualidade de Pólen Apícola. Ministério da Agricultura, Pecuária e do Abastecimento. Disponível em: http://www.apacame.org.br/mensagemdoce/52/ polen.htm. Acesso em: 10 mar. 2006.

CASTAGNINO, G.L.B.; MESSAGE, D.; MARCO JÚNIOR, P.; FERNANDES FILHO, E.I. Avaliação da eficiência nutricional do substituto de pólen por meio de medidas de áreas de cria e pólen em Apis mellifera. Revista Ceres, v.41, p.307-315, 2004. 
COOK, S.M.; AWMACK, C.S.; MURRAY, D.A.; WILLIAMS, I.H. Are honey bees' foraging preferences affected by pollen amino acid composition? Ecological Entomology, v.28, p.622-627, 2003.

CRAILSHEIM, K. The protein balance of the honey bee worker. Apidologie, v.21, p.417-429, 1990.

CRONQUIST, A. The evolution and classification of flowering plants. New York: The New York Botanical Garden, 1988. 555p.

FUNARI, S.R.C.; ROCHA, H.C.; SFORCIN, J.M.; FILHO, H.G.; CURI, P.R.; DIERCKX, G.; FUNARI, A.R.M.; ORSI, R.O. Composições bromatológica e mineral do pólen coletado por abelhas africanizadas (Apis mellifera L.) em Botucatu, Estado de São Paulo. Archivos Latinoamericanos de Producción Animal, v.11, p.88-93, 2003.

GARCIA-GARCIA, M.C.; ORTIZ, P.L.; DAPENA, J.D. Variations in the weights of pollen loads collected by Apis mellifera L. Grana, v.43, p.183-192, 2004.

GARY, N.E. Activities and behavior of honey bee. In: GRAHAN, J.M. (Ed.). The hive and the honey bee. Hamilton: DADANT \& SONS, 1993. p.185-264.

GOODMAN, L.J. Form and function in the honey bee. Cardiff: International Bee Research Association, 2003. 220p.

HILL, P.S.M.; WELLS, P.H.; WELLS, H. Spontaneous flower constancy and learning in honey bees as a function of colour. Animal Behaviour, v.54, p.615-627, 1997.

KROYER, G.; HEGEDUS, N. Evaluation of bioactive properties of pollen extracts as functional dietary food supplement. Innovative Food Science \& Emerging Technologies, v.2, p.171-174, 2001.

LORSCHEITTER, M.L. Palinologia de sedimentos quaternários do testemunho T15, cone Rio Grande do Sul, Brasil. Descrições taxonômicas, parte II: Pesquisas, v.22, p.89-127, 1989.

MARCHINI, L.C.; REIS, V.D.A.; MORETI, A.C.C.C. Composição físico-química de amostras de pólen coletado por abelhas africanizadas Apis mellifera (Hymenoptera: Apidae) em Piracicaba, Estado de São Paulo. Ciência Rural, v.36, p.949-953, 2006.

MAURIZIO, A.; LOUVEAUX, J. Pollens de plantes mellifères d'Éurope. Paris: INRA, 1965. 148p.

MELHEM, T.S.; CRUZ-BARROS, M.A.V.; CORRÊA, A.M.S.; MAKINO-WATANABE, H.; SILVESTRE-CAPELATO, M.S.F.; ESTEVES, V.L.G. Variabilidade polínica em plantas de Campos de Jordão (São Paulo, Brasil). Boletim do Instituto de Botânica, v.16, p.9-104, 2003.

MELHEM, T.S.; MAKINO, H.; SILVESTRE, M.S.F.; CRUZ, M.A.V. Planejamento para elaboração da 'Flora polínica da Reserva do Parque Estadual das Fontes do Ipiranga (São Paulo, Brasil)' Hoehnea, v.11, p.1-7, 1984.

PEREIRA, F.M.; FREITAS, B.M.; VIEIRA-NETO, J.M.; LOPES, M.T.R.; BARBOSA, A.L.; CAMARGO, R.C.R. Desenvolvimento de colônias de abelhas com diferentes alimentos protéicos. Pesquisa Agropecuária Brasileira, v.41, p.1-7, 2006.

PERNAL, S.F.; CURRIE, R.W. Discrimination and preferences for pollen-based cues by foraging honeybees, Apis mellifera L. Animal Behaviour, v.63, p.369-390, 2002.

PERNAL, S.F.; CURRIE, R.W. Pollen quality of fresh and 1-year-old single pollen diets for worker honey bees (Apis mellifera L.). Apidologie, v.31, p.387-409, 2000.

PERNAL, S.F.; CURRIE, R.W. The influence of pollen quality on foraging behavior in honeybees (Apis mellifera L.). Behavior Ecology and Sociobiology, v.51, p.53-68, 2001.

ROUBIK, D.W.; MORENO, J.E.P. Pollen and spores of Barro Colorado Island. St Louis: Missouri Botanical Garden Press, 1991. 268p. (Monograph in Systematic Botany, v.36).

ROULSTON, T.H.; CANE, J.H. The effect of pollen protein concentration on body size in the sweat bee Lasioglossum zephyrum (Hymenoptera: Apiformes). Evolutionary Ecology, v.16, p.49-65, 2002.

ROULSTON, T.H.; CANE, J.H.; BUCHMANN, S.L. What governs protein content of pollen: pollinator preferences, pollen-pistil interactions, or phylogeny? Ecological Monographs, v.70, p.617-627, 2000.

SALGADO-LABOURIAU, M.L. Contribuição à palinologia dos Cerrados. Rio de janeiro: Academia Brasileira de Ciências, 1973.291p. SCHMIDT, J.O.; BUCHMANN, S.L. Other products of the hive. In: GRAHAN, J.M. (Ed.). The hive and the honeybee. Hamilton: DADANT \& SONS, 1993. p.927-988.

SILVA, D.J. Análise de alimentos: métodos químicos e biológicos. Viçosa: Imprensa Universitária UFV, 2002. 235p.

SILVEIRA, F.A. Influence of pollen grains volume on the estimation of the relative importance of its source to bees. Apidologie, v.22, p.495-502, 1991.

SILVESTRE-CAPELATO, M.S.F.; MELHEM, T.S. Flora polínica da reserva do Parque Estadual das Fontes do Ipiranga (São Paulo, Brasil). Hoehnea, v.24, p.115-163, 1997.

SOUZA, R.C.S.; YUYAMA, L.K.O.; AGUIAR, J.P.L.; OLIVEIRA, F.P.M. Valor nutricional do mel e pólen de abelhas sem ferrão da Região Amazônica. Acta Amazônica, v.34, p.333-336, 2004.

ZERBO, A.C.; MORAES, R.L.M.S.; BROCHETTO-BRAGA, M.R. Protein requirements in larvae and adults of Scaptotrigona postica (Hymenoptera: Apidia, Meliponinae): midgut proteolytic activity and pollen digestion. Comparative Biochemistry and Physiology - Part B: Biochemistry and Molecular Biology, v.129, p.139-147, 2001.

$\overline{\text { Recebido em } 13 \text { de fevereiro de } 2007 \text { e aprovado em } 27 \text { de junho de } 2007}$ 